\title{
Correction
}

\section{Correction to: Hundred years of the Saha equation and astrophysics}

\author{
Gautam Gangopadhyay ${ }^{\mathrm{a}}$ \\ Department of Physics, University of Calcutta, 92 Acharya Prafulla Chandra Road, Calcutta 700009, India
}

Published online 2 June 2021

(C) EDP Sciences, Società Italiana di Fisica and Springer-Verlag GmbH Germany, part of Springer Nature 2021

Correction to: Eur. Phys. J. Spec. Top.

https://doi.org/10.1140/epjs/s11734-021-00005-3

In the original version of this paper the typesetter forgot to add the Appendix to the article. The missing Appendix should read:

\section{Appendix A: Brief biography of Meghnad Saha}

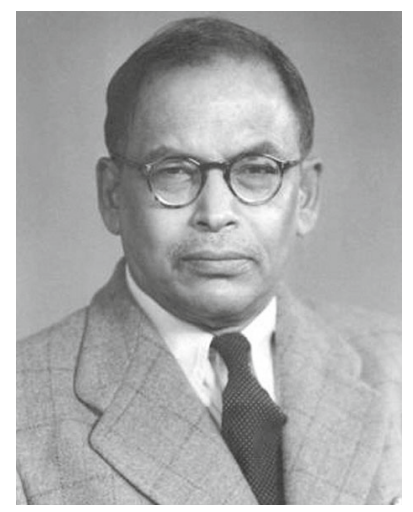

Meghnad Saha (1893-1956) was born in East Bengal in British India, now a part of Bangladesh. He studied in Presidency College, Kolkata and then joined the newly formed University College of Science of the University of Calcutta as a research fellow. Working independently, he discovered the ionization equation. After a brief stint in London and Berlin, he joined the University of Calcutta in 1921 as a professor, and in 1923 shifted to the University of Allahabad. He came back to the University of Calcutta in 1938. Within the Department of Physics he started the Institute of Nuclear Physics, which later became an independent organization and

The original article can be found online at https://doi.org/ 10.1140/epjs/s11734-021-00005-3.

\footnotetext{
a e-mail: ggphy@caluniv.ac.in (corresponding author)
}

now bears his name. He was instrumental in setting up the first cyclotron in Asia. Saha was involved in national planning and, after independence, was elected to the Indian Parliament as an independent member.

The original article has been corrected. We apologise for any inconvenience caused to our readers. 